\title{
The role of primary reinforcement and overt movements in autoshaping in the pigeon
}

\author{
MICHAEL P. BROWNE \\ Indiana University, Bloomington, Indiana 47401
}

\begin{abstract}
Following sessions of free grain delivery, a transparent shield was placed over the magazine, which made food unavailable. Different groups of pigeons then "observed" positive, zero, or negative correlations between the keylight and inaccessible grain. Keypecks were rare in all groups. Next, the shield was removed, and a transfer-test was given in which all subjects were exposed to keylight presentations followed by available grain. The previously positive group pecked sooner and more frequently than the others. A second experiment, which yielded similar results, excluded the possibility that approaches to the keylight during the observation phase had mediated learning in the first experiment. These findings were discussed in relationship to operant and Pavlovian analyses of autoshaping.
\end{abstract}

Brown and Jenkins (1968) discovered that a Pavlovian procedure, the presentation of a lighted response key followed by food, led to the conditioning of skeletal responses. Following exposure to such pairings, pigeons approach and peck the key, a finding referred to as autoshaping (see Hearst \& Jenkins, 1974, for a review).

According to one analysis, autoshaping is due not to Pavlovian processes, but is the result of adventitious ("operant") pairings of responses with reinforcement. For example, if the pigeon spontaneously pecks the lighted key during an autoshaping experiment, reinforcement follows shortly afterward. The accidental coupling increases the probability that the bird will "superstitiously" strike the lighted key on future trails. Since those pecks will also be reinforced, keypecking will become firmly established.

One way of separating stimulus-reinforcer and response-reinforcer correlations in autoshaping involves the omission or "negative-automaintenance" procedure (Williams \& Williams, 1969). The results from this procedure are consistent with the view that Pavlovian contingencies are mainly responsible for autoshaped movements.

A second technique for separating Pavlovian and operant influences in autoshaping involves permitting subjects to "observe" stimulus-reinforcer relationships without their making any directed movements or having access to the appetitive US. If subjects passively watched the stimulus-reinforcer sequence, without approaching and contacting the stimulus, operant learning could presumably not

This report is based on a dissertation submitted to Indiana University. The research was supported by NIMH Grant MH 19300 to Eliot Hearst and a grant from the graduate school of Indiana University. I am grateful for the generous contributions of Eliot Hearst and James Dinsmoor to this work, and extend my thanks to Roger Rhodes for running subjects. occur, since there would be no approach movements to be strengthened.

The question of whether subjects can learn merely by watching, without acting, is related to a persistent conflict in theories of animal learning, the' question of what is learned. According to cognitive theories, learning is mainly a matter of gaining knowledge about relationships between events. On the other hand, according to stimulus-response theories, learning is primarily a matter of forming associations between responses and stimuli. During the 1930s and 1940s, the validity of the two views was debated furiously, but inconclusively. Partially as a reaction against the inconclusive nature of the debates and partially due to the strong anti-theoretical influence of Skinner, issues surrounding the question of what is learned were avoided during the 1950s and 1960s. Nevertheless, the general issues seem to be important ones, which ought to be discussed and investigated.

The two experiments presented here are an attempt to evaluate the role of overt movements and primary reinforcement in the development of autoshaped behavior. The general plan allowed pigeons to observe presentations of the keylight and activations of the grain magazine at times when access to the grain was blocked by a clear Plexiglas shield. After this observation period, the grain was made available to the subject and development of autoshaped behavior was examined as a function of the type of contingency between the keylight and the grain which the subject had initially observed.

\section{EXPERIMENT I}

Method
Subjects
Forty naive female White Carneaux pigeons were each tested
daily at approximately the same time and were maintained at


$75 \%$ of their free-feeding weights. Supplementary grain was given to the pigeons in their home cages immediately following sessions during which they did not receive sufficient grain to maintain their weights.

\begin{abstract}
Apparatus
Pigeons were tested in identical Lehigh Valley two-key pıgeon chambers. Only the left-hand key was used. When the magazine was raised into position, the lamp above it was lighted, and the couselight, which otherwise remained lighted throughout all experimental sessions, was extinguished. A fan ventilated each chamber, and white noise masked external sounds. The experimental procedures were controlled by electromagnetic equipment located in an adjacent room.
\end{abstract}

\section{Procedure}

The experiment had three consecutive phases: magazine training and free grain delivery, observation of contingencies, and an autoshaping transfer test.

Magazine and training and free grain delivery. During the first session, the pigeon was trained to approach promptly and eat from the magazine when it was raised. For the following five sessions, the pigeons received presentations of free, unsignaled grain according to a variable time schedule with a mean of $60 \mathrm{sec}$ (VT $60 \mathrm{sec}$ ) and a range of 15 to $120 \mathrm{sec}$. During these sessions and throughout the rest of the experiment, magazıne presentations lasted for $5 \mathrm{sec}$, and each session ended after about 60 presentations. The pigeon's behavior never affected presentation of the grain.

Observation of contingencies. During the next three sessions, the opening which led to the magazine was covered with a piece of transparent Plexiglas. When the magazine was raised, the grain wras visible but not accessible. Four groups "observed" the presentation of the CS (6-sec illumination of the response key with white light) in some temporal relation to the presentation of inaccessible grain. For the Positive group, the CS was presented according to a VT 60 -sec schedule, and simultaneously with CS offset the magazine was raised. For the Random group, the CS and the magazine were presented according to independently cperating VT 60 -sec schedules. For the Negative-26 group, CS presentations and magazine presentations were programmed by separate VT 60 schedules. Onset of the CS initiated a 26-sec negative period $(6 \mathrm{sec}$ while the key was lighted and the immediately succeeding $20 \mathrm{sec}$ ), during which neither schedule was 111 operation; hence, no magazine presentations or CS presentatıons were made during this time. Both schedules also ceased to operate during the 5 -sec magazine presentations. The procedure for the negative-86 group was the same except that the negative period following each onset of the CS lasted for $86 \mathrm{sec}$. The US-only group, a fifth group, received presentations of the inaccessible magazine according to a VT $60-\mathrm{sec}$ schedule, but the key was never lighted.

Autoshaping transfer test. Then the transparent shield was removed from the opening to the magazine. At the start of the next session, after the pigeon had been placed in the chamber, the magazine was rassed and held in that position until the pigeon had eaten from it for $5 \mathrm{sec}$. Most subjects ate within $30 \mathrm{sec}$, but one to three subjects in each group did not eat until 15 to $20 \mathrm{~m} / \mathrm{n}$ had passed. Subsequently, grain was delivered two additional tumes for $5 \mathrm{sec}$. This magazine training was conducted to make certain that all birds had discovered gran was again available and would readily eat from the magazine during the test sessions which followed.

The autoshaping transfer test followed immediately afterward. For subjects in all groups, trials consisting of the 6-sec CS followed by immediate presentation of grain occurred according to a VT 60)-sec schedule. This procedure continued during the remainder of the session and four subsequent sessions.

\section{Results \\ Observation of Contingencies}

There was little pecking of the lighted response key by the subjects from any of the groups during this phase (see left panel of Figure 1). The positive group subjects did peck slightly more-on an average of $1.5 \%$ of all trials; animals in the other groups pecked on $0.5 \%$ to $1.0 \%$ of the trials. However, nonparametric one-way analysis of variance tests for the three sessions combined indicated that differences between the groups were not significant for the two measures, percent of trials with a response or responses per trial.

Visual observation of the Positive birds and Negative birds revealed no tendencies for the pigeons to approach or withdraw from the CS. In fact, throughout the second and third sessions many of the animals in all groups crouched almost motionless in the chamber.

\section{Autoshaping transfer test}

When the keylight preceded available food, Positive birds pecked sooner, on a greater proportion of trials, and at higher rates than the birds from other groups. Table 1 gives the trial of the first peck for the pigeons in each group. A one-way analysis of variance revealed a significant treatment effect $(\mathrm{H}=11.7, \mathrm{df}=\mathbf{4}, \mathrm{p}<.02) .{ }^{1}$ Rank tests showed that the Positive group made its first peck significantly earlier than any of the other groups (Us $\leqslant 11$, ps $<.03) .^{2}$ No other between-group comparisons yielded statistically significant differences with regard to this measure.

The right-hand panel of Figure 1 shows acquisition curves during the five sessions of autoshaping for the precentage of trials with a response. For the first session, an analysis of variance test showed a significant treatment effect $(H=10.0, \mathrm{df}=4$, $p<.05)$. Rank tests revealed that differences between the Positive and 'US'-only groups were not significant, but the Positive group was superior to the Random and Negative groups (Us $\leqslant 11$, ps $<.03$ ). The 'US'-only group pecked on a significantly greater portion of trials than either of the Negative groups (Us $\leqslant 11$, ps $<.03$ ). Differences between the 'US'only and Random groups, as well as differences between the Random and Negative groups, were not significant. An analysis of variance did not reveal a significant treatment effect for Session 5 .

The data for the rate of pecking (shown in Figure 2) paralleled the data for the percent of trials with a response. There was a significant treatment effect for Session $1(\mathrm{H}=11.6$, df $=4, \mathrm{p}<.03)$. During this session, the Positive subjects responded at significantly higher rates than subjects from the Random and Negative groups (Us $\leqslant 13$, ps $<.05$ ), 
Table 1

Trial of the First Response During the Test Sessions of Experiment I

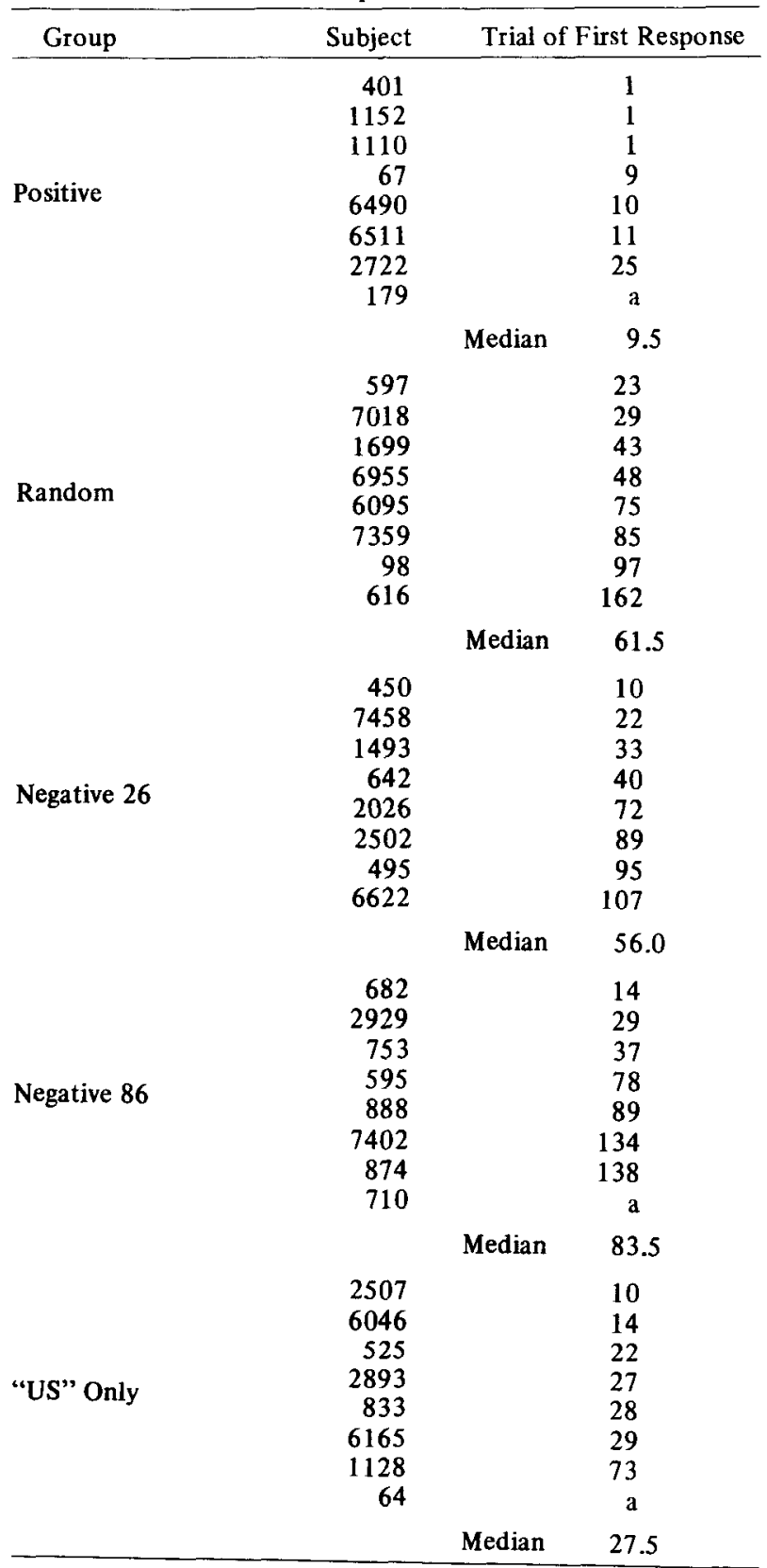

Note-During prior sessions, subjects received various correlations between the lighted key and inaccessible grain. During the test sessions, the keylight was followed by available grain.

a-Never pecked during five test sessions

but did not differ significantly from the 'US'-only group. The 'US'-only group was superior to both of the Negative groups (Us $\leqslant 8$, ps $<.01$ ), but not to the Random group, and the Random group did not differ significantly from the Negative groups. There was no significant treatment effect for Session 5.

\section{Discussion}

The pigeons in all groups pecked infrequently during the period when grain was inaccessible; there was no evidence that the positive birds had been conditioned to peck the key. Later, when all pigeons were exposed to the keylight followed by available food, however, the Positive group pecked significantly sooner, on a greater proportion of trials, and at higher rates than the Random or Negative groups. Differences between the Positive and 'US'-only subjects were small; the two groups differed significantly only with respect to the trial of the first peck.

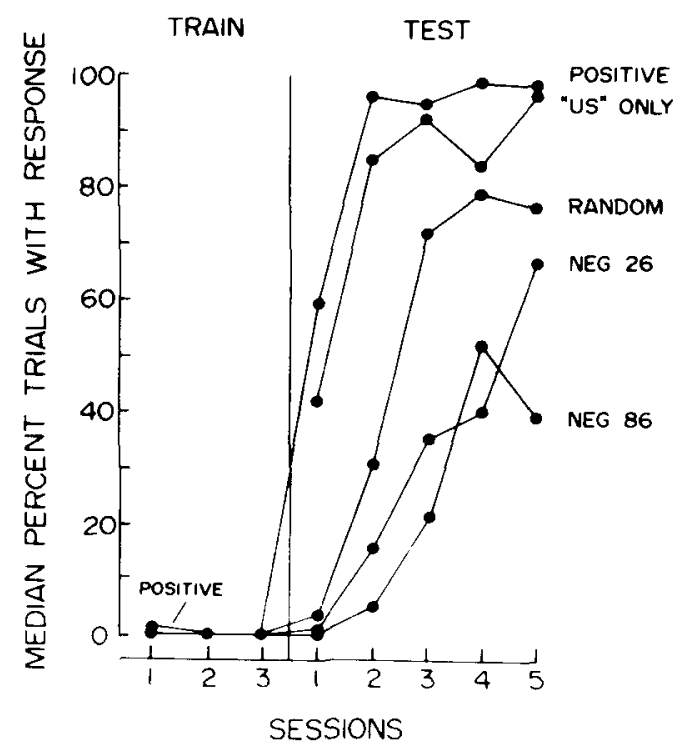

Figure 1. Median percent of trials on which pigeons pecked the lighted key during Experiment I. On the left (train), groups of birds received various temporal correlations between the lighted key and inaccessible grain. On the right (test), all pigeons received presentation of the lighted key followed by available grain.

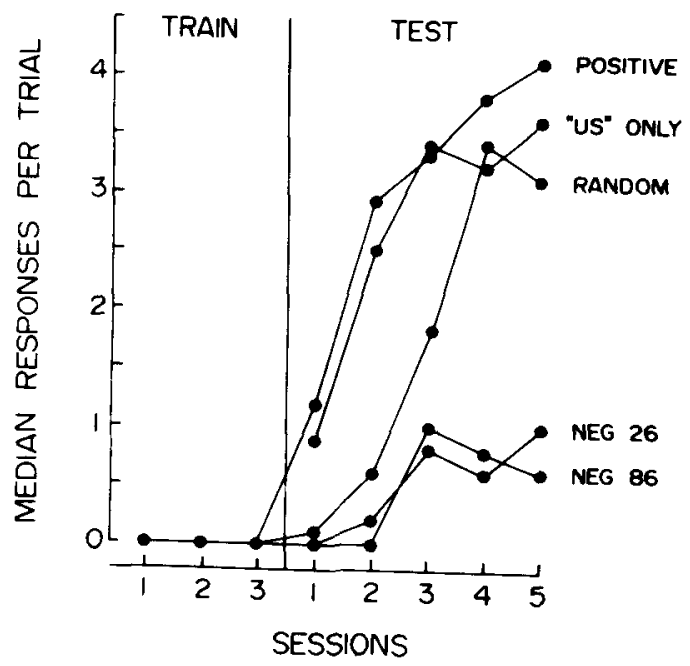

Figure 2. Median number of responses per trial. Details as in Figure 1. 
Does this pattern of findings indicate that the Positive group learned relatively little about the relationship of the keylight to the magazine during the observation phase, whereas the Random and Negative groups learned, respectively, that the keylight conveyed to information or that it predicted periods without grain? Since the Positive and 'US'only groups differed significantly with repect to the trial of the first peck, it seems likely that the former group did learn the CS-'US' relationship during observation training. The 'US'-only group conditioned rapidly: half of the pigeons pecked on more than $50 \%$ of the trials during the first session. Apparently, these animals quickly overcame the advantage observation training provided to the Positive birds.

The contrasting performances of the Positive group, on the one hand, and the Random and Negative groups, on the other, demonstrate that pigeons learn the relationship between a neutral stimulus and grain in the absence of primary reinforcement and without performing pecking movements. Although the shield prevented the subjects from obtaining primary reinforcement, conditioned reinforcement could have been involved. In the first phase, the magazine stimuli (the noise caused by the impact of the activated hopper, the lighting of the magazine lamp, and the sight of grain) had preceded and accompanied eating. As a result, those stimuli probably acquired reinforcing powers. Accordingly, when the magazine was raised behind the transparent shield, the stimuli might have reinforced immediately preceding responses.

The fact that the pigeons learned the CS-'US' relationship even though only rarely pecking the key is incompatible with an analysis of autoshaping based on the accidental reinforcement of pecking. In addition, visual surveillance of the subjects throughout the three sessions did not reveal movements toward the key or away from it (see Wasserman, Franklin, \& Hearst, 1974). On the contrary, following the initial half of the first training session many subjects spent nearly all of the balance of observation training crouched nearly motionless facing the magazine. Because these findings indicate that movements did not mediate the test results, they are inconsistent with accounts of autoshaping which stress response-reinforcer pairings.

Unfortunately, the pigeons were observed intermittently, rather than on every trial, and the possibility remained that some approach or withdrawal movements had occurred. Therefore, a second experiment was performed in which these movements were monitored continually by means of automatic devices.

\section{EXPERIMENT II}

A chamber, $75 \mathrm{~cm}$ long (over twice the length of the chamber used in Experiment I), was employed. The large chamber allowed relatively wide separation of the response key from the magazine, which in turn made it possible to record automatically approach to the key and withdrawal from it. Two groups were tested, a Positive group and a Negative-26 group, each trained on procedures similar to those used for the corresponding groups in Experiment I.

\section{Method}

Subjects

Six White Carneaux and six Autosex pigeons were naive females. They were treated in the same manner as the birds in Experiment I. An equal number of each kind of pigeon served in each experimental group.

\section{Apparatus.}

The chamber measured $75 \mathrm{~cm}$ long and $30 \mathrm{~cm}$ deep. A floor plan is shown in Figure 3. The front wall of the chamber contained a houselight and a grain magazine. A black plastic box, $5 \times 10 \times 4 \mathrm{~cm}$, was fastened to the left wall of the chamber $21 \mathrm{~cm}$ from the floor and $8 \mathrm{~cm}$ from the edge of the front wall. A response key appeared through a hole, 2.2 in. in diameter, on the front of the box. Noise from an exhaust fan and white noise generator masked external sounds.

The specially constructed floor used to record the pigeon's position in the chamber was divided into three $30 \times 25 \mathrm{~cm}$ sections (see Figure 3). The center section was made of plywood about $2.0 \mathrm{~cm}$ thick, and attached to it on both sides by hinges were Plexiglas panels about $0.4 \mathrm{~cm}$ thick. Support springs were mounted beneath the far corners of each Plexiglas panel and a pressure-activated microswitch was positioned at the midpoint of the outer edge of each panel. When a pigeon stepped onto one of the side panels, the switch beneath that panel was operated.

\section{Procedure}

Magazine Iraining and free grain delivery. On the first day, the pigeons were magazıne trained as in Experiment I, and for the 6 succeeding days received unsignaled deliveries of free grain according to a VT $60-\mathrm{sec}$ schedule. During these sessions and throughout the rest of the experiment, magazine presentations lasted $6 \mathrm{sec}$ and were accompanied by the extunction of the houselight, which was otherwise illuminated throughout the session. Throughout the experiment, sessions ended after 50 operations of the magazine.

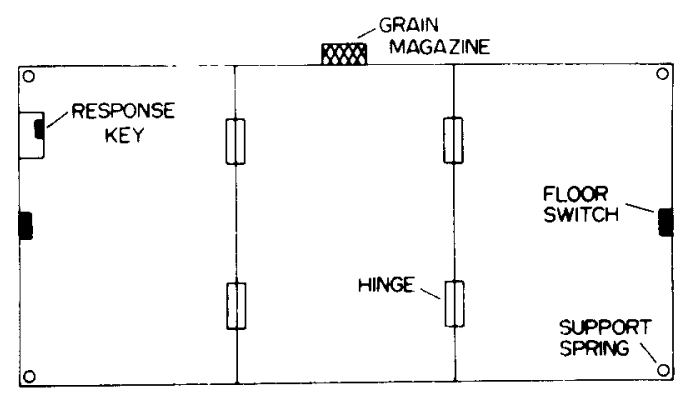

Figure 3. Top view of the chamber used in Experiment II. Additional details are given in text. 
Observation of contingencies. Following the sessions of free grain presentation, the subjects were divided into a Positive group and a Negative group. During this phase the opening that led to the magazine was covered with transparent Plexiglas, and for three sessions the pigeons received temporal correlations of the CS (6-sec illumination of the key with white light) with the presentation of the inaccessible magazine. For the Positive group, trials consisting of the CS followed immediately by a 6-sec magazine presentation were scheduled randomly, with an average of $60 \mathrm{sec}$ between trials. For the Negative group, CS presentations and operations of the magazine each occurred randomly with an average interval of $60 \mathrm{sec}$ between presentations. However, at least $26 \mathrm{sec}$ always elapsed after onset of the CS before the magazine was presented.

Autoshaping transfer test. Prior to the start of the first test session, the pigeons received a brief period of magazine training. At this stage in Experiment $I$, the magazine was merely raised and held up. On that procedure, however, a number of birds did not begin eating for several minutes. Therefore, a slightly different procedure was used in Experiment 11. After the shield had been removed, the magazine was raised and filled with grain. When placed in the chamber, most birds began to eat within $30 \mathrm{sec}$; however, 3 of the 12 pigeons did not eat for about $10 \mathrm{~min}$. Two of the three birds were from the Posituve group. After the pigeon had eaten for $6 \mathrm{sec}$, the magazine was lowered and then raised again three additional times for $6 \mathrm{sec}$ each. Following this short period of magazine training, the actual test began. All pigeons received the Positive procedure used in pretraining, except, of course, now the subjects could eat the grain whenever the magazine was raised. There were five test sessions.

During the observation and test phases, the pigeon's position in the chamber was measured during the CS periods and during an equal number of randomly scheduled 6-sec "dummy" periods. In order to calculate an index of the pigeon's tendency to approach the lighted key, two percentages were calculated: (A) the percentage of CS time the pigeon stood on the left side of the floor (near the key) and (B) the percentage of dummy time spent standing on that side. Since the second percentage indicates the amount of nonstimulus time normally spent in the left-hand section of the chamber, the index of CS-controlled approach was calculated by subtracting (B) from (A). A positive number indicates that the subject approached the CS.

A second index was calculated to provide a measure of withdrawal from the CS for the Negative group. Again, two percentages were calculated: (A) the percentage of CS time the subject stood on the right panel of the floor (far from the key) and (B) the percentage of dummy time the pigeon stood on the right. To provide the withdrawal index, $(B)$ was subtracted from the CS.

The subtraction index was selected rather than a ratio, because when a ratio is used, if either of the numbers equals zero for a session the ratio gives no information about the other number. During the training phase, as well as during the initial sessions of testing, many subjects had a score of zero for one of the two percentages.

\section{Results \\ Observation of Contingencies}

The Positive subjects did not approach the lighted key during the sessions of training with inaccessible grain, and the Negative subjects did not withdraw from it. For the Positive subjects an approach index greater than zero indicates that the pigeon approached the lighted key, but of 18 data points (six pigeons $\times$ three sessions), 16 points were zero or less. The median approach index equaled zero for each session. For the Negative animals, a withdrawal index greater than zero indicates that the subject withdrew from the key, but 12 of the 18 data points were zero or less. The median withdrawal index for each session equaled zero.

The keypeck data also failed to reveal the conditioning of movements. During the observation sessions, two pigeons in each group pecked the lighted key. The two Positive animals together made 22 pecks on a total of six trials, while the Negative subjects made 10 pecks on two trials. These differences, of course, were not significant.

\section{Autoshaping Transfer Test}

In Figure 4, median approach indices are plotted for successive sessions of training (left panel) and testing (right panel). The Positive group approached the lighted key significantly more than the Negative group on the first day of testing $(U=5, p<.05)$, but thereafter the differences were not significant.

Although the Positive birds began pecking sooner than the Negative animals, the two groups did not differ significantly with respect to this measure or any other measure of keypecking. In fact, neither

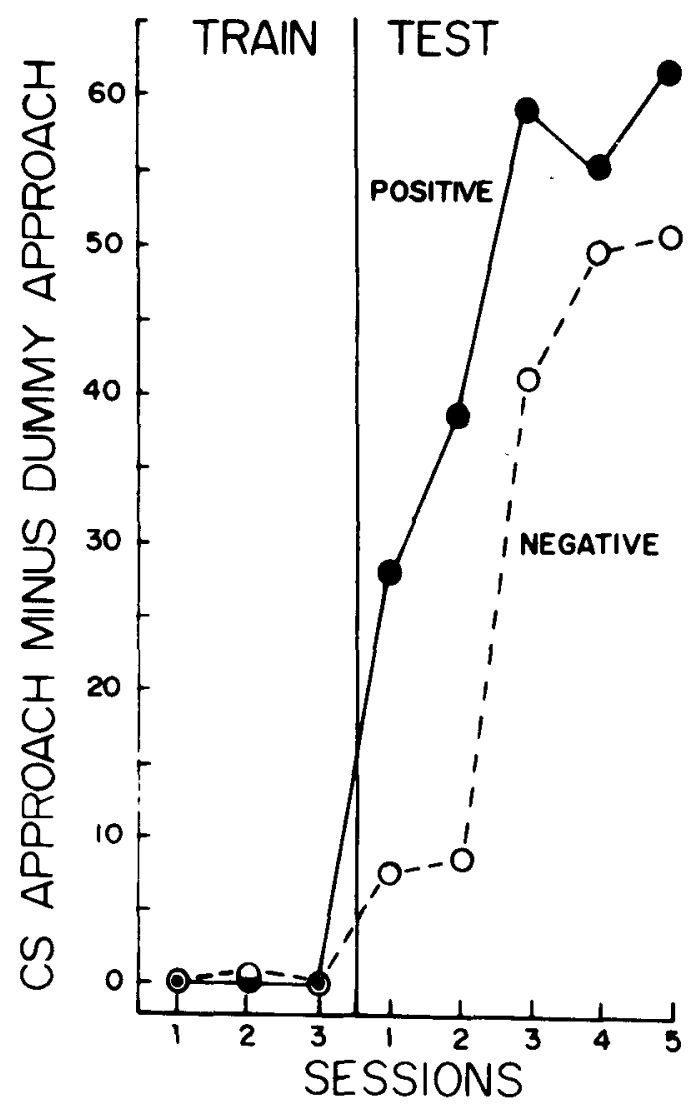

Figure 4. Median approach index for the two groups of subjects during Experiment II: the percent of CS time standing in the left third of the chamber (near the key) minus the percent of dummy trial time spent in the same location. On the left (train), pigeons received positive or negative correlations between the lighted key and inaccessible grain. On the right (test), both groups received the lighted key followed by available grain. 
group ever came to peck the key reliably. For instance, on the fifth day of autoshaping, only three of the six pigeons in each group pecked on a majority of trials.

\section{Discussion}

During training with the magazine covered by a transparent shield, the Positive animals did not learn to approach the keylight, which signaled the impending activation of the magazine, nor did the Negative subjects learn to withdraw from the keylight, which for these birds signaled that the inaccessible magazine would not be raised. However, when the keylight was paired with available grain during the test which followed, the Positive subjects learned to approach it significantly sooner than the other pigeons.

Both groups failed to acquire reliable keypecking during the test, and as a result, the two groups did not differ significantly with respect to any measures of pecking. They probably pecked less here than in the first experiment due to the increased distance between the key and the grain magazine.

These two experiments show that a positive relationship between a CS and an out-of-reach US still results in a tendency to approach and contact the key when the barrier is removed. Since the subjects did not learn to approach or peck the key during the observation phase, they apparently acquired information about stimulus-stimulus relations during that period, rather than learning any overt movements. Thus the present findings are consistent with the general cognitive notion that the subjects in animal learning experiments may learn about relationships between environmental events rather than, or in addition to, simple associations between stimuli and responses.
The present findings are inconsistent with an operant analysis of autoshaping. Since overt movements were not apparently conditioned during the initial phase, the subsequent emergence of approach and contact behaviors would seem to depend on Paylovian contingencies, and not on response-reinforcer relationships. ${ }^{3}$

\section{REFERENCES}

Brown, P. L., \& Jenkins, H. M. Auto-shaping of the pigeon's keypeck. Journal of the Experimental Analysis of Behavior, $1968,11,1-8$.

Hearst, E., \& Jenkins, H. M. Sign-tracking The stimulusreinforcer relation and directed action. Austin. Texas: The Psychonomic Society, 1974.

Parisi, T., \& Matthews, T. J. Pavlovian determinants of the autoshaped keypeck response. Bulletin of the Psychonomic Society, 1975, 6, 527-529.

Wasserman, E., Franklin, S., \& Hearst, E. Pavlovian appetitive contingencies and approach versus withdrawal to conditioned stimuli in pigeons. Journal of Comparative and Physiological Psychology, 1974, 88, 616-627.

Williams, D. R., \& Williams, H. Auto-maintenance in the pigeon: Sustained pecking despite contingent nonreinforcement. Journal of the Experimental Analysis of Behavior, 1969, 12, 611-620.

\section{NOTES}

1. The Kruskal-Wallis was used for the multigroup analyses.

2. The Mann-Whitney $U$ test (two-tailed) was used for all two-group comparisons reported.

3. Since this paper was initially submitted for publication, Parisi and Matthews (1975) have published a report confirming the major findings described here.

(Received for publication November 11, 1974; revision accepted February, 1976.) 